\title{
A huge benign mucinous cystadenoma of ovary: a case report and review of literature
}

\author{
Rajshree D. Katke*
}

Department of Obstetrics \& Gynaecology, Cama \& Albless Hospital, Govt. Grant Medical College Mumbai, Maharashtra, India

Received: 15 March 2014

Revised: 19 March 2014

Accepted: 23 March 2014

\section{*Correspondence:}

Dr. Rajshree D. Katke,

E-mail: drrajshrikatke@gmail.com

(C) 2014 Katke RD. This is an open-access article distributed under the terms of the Creative Commons Attribution Non-Commercial License, which permits unrestricted non-commercial use, distribution, and reproduction in any medium, provided the original work is properly cited.

\begin{abstract}
Ovarian tumour is not a single entity, but a complex wide spectrum of neoplasms involving a variety of histological tissues. The most common are the epithelial tumours forming $80 \%$ of all tumours. $80 \%$ are benign tumours, $10 \%$ borderline malignant and $8-10 \%$ malignant. Mucinous tumours represent about $8-10 \%$ of the epithelial tumours, they may reach enormous size filling the entire abdominal cavity. ${ }^{1}$ Here we would like to present a case of huge benign mucinous cystadenoma in a 50 year old female where the patient could not access medical care, and presented with huge tumour which lead to breathlessness and responded remarkably to surgical excision. The patient could go back to her normal life following the procedure.
\end{abstract}

Keywords: Huge benign mucinous cystadenoma, Mucinous cystadenoma

\section{INTRODUCTION}

Benign ovarian mucinous tumors are rare at the extremities of age, before puberty and after menopause. They are common between the third and the fifth decades. Mucinous cystadenomas may reach huge size as a matter of fact; many of the largest human tumours belong to this group. Grossly these tumours appear as rounded, ovoid or irregularly lobulated growths with a smooth outer surface of whitish or bluish white hue. The wall in many areas is so thin as to be translucent. Although adhesions to surrounding organs may be present, they usually represent inflammatory adhesions and do not connote malignant extension. They are attached to the infundibulopelvic ligament by a relatively narrow pedicle that contains the markedly increased supply for the tumour. The content of the cyst is generally a clear viscid fluid, sometimes very thick at other times thin; a mixture of blood elements may give it a chocolate or brownish hue. This fluid is usually rather thin and flows freely at body temperature, but congeals and becomes gelatinous as it cools. The cut surface shows the cavity to be divided by septa into varying number of compartments or locules, these tumours have therefore often been spoken as a multilocular cyst. Microscopically, the distinctive feature of mucinous cysts is the characteristic single layer often undulating outline, of tall, pale-staining secretory epithelium, with nuclei placed at the basal poles of the cells, goblet cells are often seen, on occasion, even paneth and argentaffin cells are noted. Pseudomyxomaperitonii is often associated with mucinous cyst of ovary and mucocele of appendix and carcinoma of large bowel. ${ }^{2}$

\section{CASE REPORT}

A 40 year female married since 30 years P1L1, postmenopausal since 15 years presented on $30 / 11 / 13$ with complaint of abdominal distension and pain since 6 months. Patient consulted at municipal hospital thane, but symptoms were not relieved. On 25/09/13, CA 125 was $7.2 \mathrm{U} / \mathrm{ml}, \mathrm{CEA}$ was $79 \mathrm{U}$ (raised) and AFP - $3.3 \mathrm{U} / \mathrm{ml}$. 
On examination, her pulse rate was 82 beats/min, BP $124 / 80 \mathrm{mmHg}$. She was mildly pale. No lymphadenopathy on general examination. Breast examination was normal findings. On per abdomen examination - abdomen was markedly overdistended all over. The skin was overstretched with prominent veins on it. On palpation there is a very large palpable mass arising from the pelvis extending to the epigastrium and extended diffusely in both the flanks and all over the abdomen. Consistency was cystic and at some places firm. With large palpable lump with diffuse ill-defined margins arising from pelvic region to epigastric region with lower margins not palpable. Fluid Thrill was positive. On 03/12/13, all haematological investigations were normal; Pap smear done on 5/12/13 was suggestive of atrophic smear with no evidence of malignancy. On 06/1 CT SCAN done on 09/12/13 was suggestive of predominantly cystic large lesion $18.4 \mathrm{~cm}$ x $30 \mathrm{~cm}$ x 32 $\mathrm{cm}$ in abdominopelvic region with minimal thickened septae, probably serous / mucinous cystadenocarcinoma.

ON 13/12 /13, exploratory laparotomy with tumour mass excision with frozen section with total abdominal hysterectomy with bilateral salpingo-oophorectomy done under general and epidural anesthesia. Abdomen was opened by taking midline incision. After opening the rectus sheath the rectus muscle adherent to the posterior rectus sheath with cautery the adhesions separated. After that the thin out peritoneum completely fused with the wall of the cyst all over and at some places the posterior rectus sheath, peritoneum and cyst wall fused completely and formed like one layer of the cyst wall. At some places the peritoneum wall was very much thinned out because of overstretching. There was no way to go to the tumour so decompression of the tumor was done by taking out the mucinous jelly like material of 10 liters drained. After that we were able to go the peritoneal cavity. There was a huge tumour extended to all over the abdomen $60 \mathrm{~cm} \times 40 \mathrm{~cm} \times 35 \mathrm{~cm}$. It is soft, cystic, yellowish tumour spreading all over. Posteriorly it was adherent to the colon the adhesions were separated with fine dissection and cautery. There was another extension of the tumour which is cystic mucinous tumour of size 25 $\mathrm{cm} \times 30 \mathrm{~cm} \times 28 \mathrm{~cm}$ from the left ovary adherent to the left ureter and below to urinary bladder. Careful dissection helped in separating tumour from the left ureter and urinary bladder. The huge tumour separated all the sides then delivered out and confirming the position of the both the ureters keeping them away the pedicle sealed and cut with cautery. Taken out the tumour successfully. The total weight of the tumour measured as $20 \mathrm{~kg}$. (Twenty $\mathrm{kg}$ ) haemostasis achieved by ligating the vessels and ligating the pedicles. Total abdominal hysterectomy with right sided salpingo-oophorectomy with removal of huge ovarian tumour done. The omentum was yellow jelly like. Surgeon explored the bowel to see any other site of involvement of intestine. Frozen section report came as Benign Mucinous cystadenoma of the ovary, so pelvic lymph node dissection was not done. Thorough wash was given.

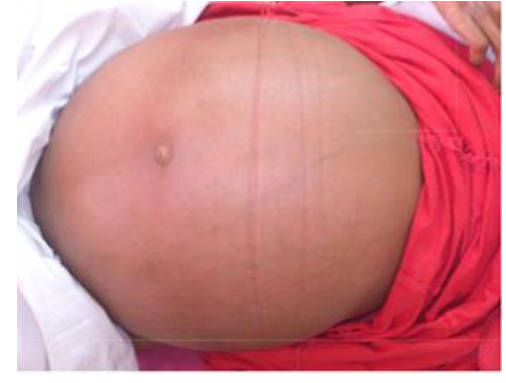

Figure 1: Shows huge mucinous cystadenoma of the ovary extending all over the abdomen.

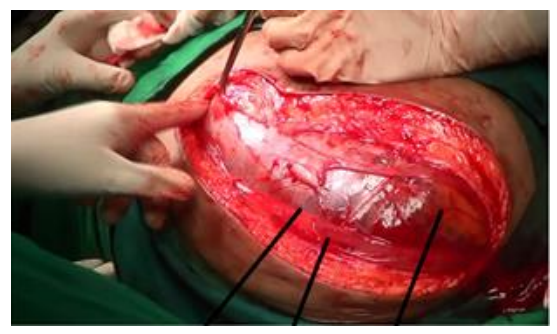

Figure 2: The rectus sheath, muscle and peritoneum adherent to the cyst wall and fused to become one layer.

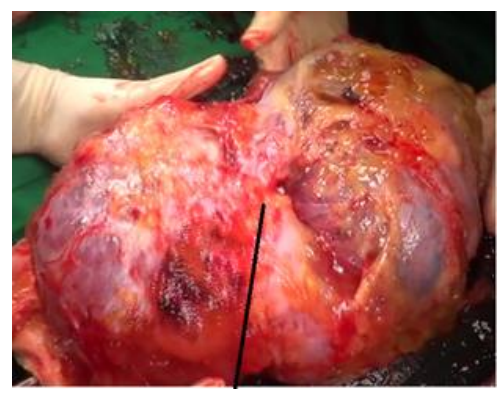

Figure 3: Shows huge mucinous tumour of ovary (20 $\mathrm{kg}$ in total).

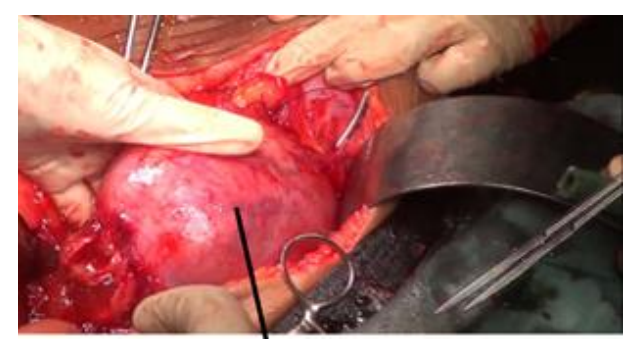

Figure 4: Left ovarian tumour weighing $3 \mathrm{~kg}$.

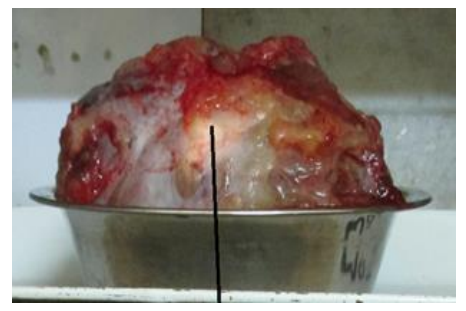

Figure 5: Huge ovarian tumour of $20 \mathrm{~kg}$. 

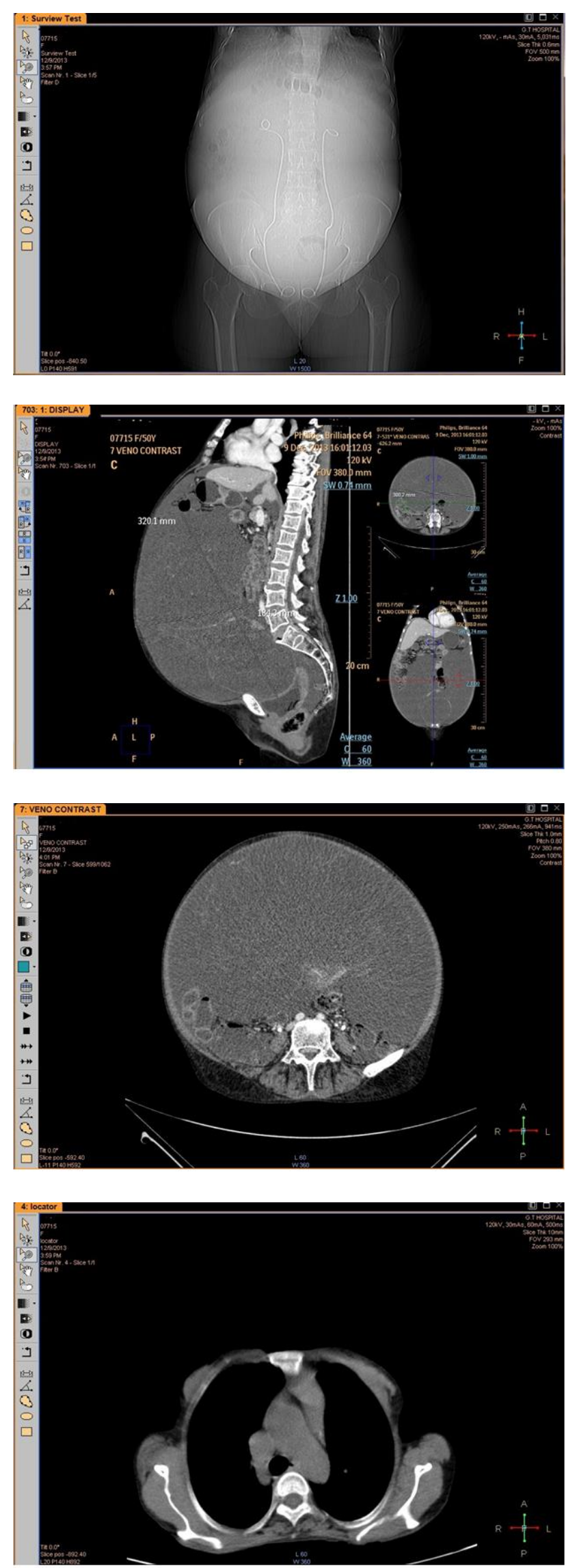

Figure 6: Computerized tomography imaging pictures of the ovarian tumour.
Haemostasis achieved completely, after checking the counts of instruments and sponges. Abdomen closed in layers after keeping the drain in situ. Blood loss during surgery was average. Her postoperative period was uneventful. Stiches were taken out. Bilateral ureteric stents removed and patient discharged. Patient came for follow up; she was fine and resumed the work.

\section{DISCUSSION}

Mucinous tumours of the ovary are usually evaluated using ultrasound, computerized tomography scan, or magnetic resonance imaging. These ovarian tumors may be multi-septated, cystic masses with thin walls. They may contain varying amounts of solid tissue which consists of proliferating stromal tissue, papillae, or malignant tumor cells. Tumour markers may also aid us in telling us the origin of the tumour. ${ }^{3}$ Benign mucinous cystadenomas comprise $80 \%$ of mucinous ovarian tumors and $20 \%-25 \%$ of benign ovarian tumours overall. The peak incidence occurs be-tween 30 - 50 years of age. Benign tumors are bilateral in $5 \%-10 \%$ of cases. Borderline mucinous cystadenomas make up about $10 \%$ of mucinous ovarian neoplasm's and are bilateral in $10 \%$ of cases.

In the modern era of medicine, such huge mucinous ovarian tumours have become rare in the current medical practice, as most of the cases are diagnosed early during routine gynaecological examinations or incidental finding on the ultrasound examination of the pelvis and abdomen. Most of the patients who have large tumours they present mainly with the pressure symptoms over the genitourinary system leading to urinary complaints and also pressure over respiratory system leads to respiratory embarrassment. The role of imaging modalities like CT scan and MRI gives better idea about the extension of the tumour in the various quadrants of the abdomen and consistency of the tumour. Management of ovarian cysts depends on the patient's age, the size of the cyst and its histo-pathological nature. Conservative surgery as ovarian cystectomy and salpingo-oophorectomy is adequate for benign lesions. ${ }^{4}$ Frozen section is very important to know the malignant variation of this tumour and that helps in the management of the patient. As in the huge tumours, the anatomical planes get distorted, so the surgical expertise is required to prevent the complications.

Funding: No funding sources

Conflict of interest: None declared

Ethical approval: Not required

\section{REFERENCES}

1. Wilfred Shaw, John Howkins, Gordon Lionel Bourne. Disorders of the ovary and benign tumours. In: Wilfred Shaw, John Howkins, Gordon Lionel Bourne, eds. Shaw's Textbook, 14th ed. London: Churchill Livingstone; 2008: 334. 
2. Howard W. Epithelial ovarian cancer. In: Jones, Anne Colston Wentz, Lonnie S. Burnett, eds. Novak's Textbook of Gynaecology. 11th ed. UK: Williams \& Wilkins; 1988: 806-809.

3. Crum CP, Lester SC, Cotran RS. Pathology of female genital system and breast. In: by Kumar V, Abbas A, Fausto N, Mitchell R, eds. Robbins' Basic Pathology. 8th ed. USA: Elsevier Company; 2007: Chapt. 19.
4. Alobaid AS. Mucinous cystadenoma of the ovary in a 12-year-old girl. Saudi Med J. 2008;29(1):126-8.

DOI: $10.5455 / 2320-1770 . i j r \operatorname{cog} 20140636$

Cite this article as: Katke RD. A huge benign mucinous cystadenoma of ovary: a case report and review of literature. Int J Reprod Contracept Obstet Gynecol 2014;3:456-9. 